\title{
ARTICLE \\ Impact of Coronavirus Anxiety on Depressive Tendencies among Emerging and Young Adults
}

\section{Vanshika Beri*}

Amity Institute of Psychology and Allied Sciences, Amity University Campus, Noida, Uttar Pradesh, India

\begin{tabular}{|c|c|}
\hline ARTICLE INFO & ABSTRACT \\
\hline Article history & \multirow{8}{*}{$\begin{array}{l}\text { Coronavirus, our new chemical enemy, have become successful in chang- } \\
\text { ing our lives to an extent that now we have to think twice before stepping } \\
\text { out of house. It has impacted negatively on not only our physical health } \\
\text { but also psychological health. The current study was done to see the im- } \\
\text { pact of coronavirus related anxiety on depressive tendencies. Further, it } \\
\text { was assessed whether there is any interaction between gender and coro- } \\
\text { navirus anxiety on depressive tendencies. The linear regression indicated } \\
\text { that coronavirus anxiety is strongly related to depressive tendencies and } \\
\text { that the coronavirus anxiety is a predictor of depressive tendency. How- } \\
\text { ever, two-way ANOVA indicated that there is an insignificant difference } \\
\text { as to how males and females face depressive tendencies. Finally, there is } \\
\text { insignificant interaction between gender and coronavirus anxiety on de- } \\
\text { pressive tendencies. The implications, limitations and future suggestions } \\
\text { are also given on the basis of the findings so obtained. }\end{array}$} \\
\hline Received: 15 March 2021 & \\
\hline Accepted: 16 April 2021 & \\
\hline Published Online: 10 May 2021 & \\
\hline Keywords: & \\
\hline Covid-19 pandemic & \\
\hline Coronavirus related anxiety & \\
\hline Depressive tendencies and mental health & \\
\hline
\end{tabular}

\section{Introduction}

The world has faced a lot of pandemics from time to time. But this time we have got a chemical enemy which spreads with touch and there is no chance that it will stop itself any sooner. The coronavirus (COVID-19) has been declared as a pandemic by the World Health Organization on March 11, $2020^{[1]}$. Governments around the world had to take stringent measures, like the implementation of lockdown, to break its chain. All educational institutions, huge organizations, and factories had to shut down as a result of lockdown. People who were going out of their houses had to behave differently because of social distancing. All of this led to a sudden shift in daily routine, with which some people were able to cope, and some faced difficulties and adjustment issues ${ }^{[2]}$.

The stress of lockdown and coronavirus has affected a lot of people in many different ways. Many pieces of research have been done around the world to assess the mental health of people during these difficult times. A study with a huge sample, done in Italy found that a huge proportion of their sample was facing anxiety and depressive symptoms along with sleep disturbances ${ }^{[3]}$. A similar study done in Italy reported problems of insomnia, anxiety, depression, adjustment problems, and high perceived stress ${ }^{[2]}$. Similar results were observed in Austria ${ }^{[4]}$ and China ${ }^{[5,6]}$. Many studies have also been done in the Indian context to assess the mental health of the Indian population in the time of coronavirus. Sathyamurthi et al reported that anxiety and stress are the most common coronavirus reactions ${ }^{[7]}$.

Studies are also done to examine gender differences. Most of the studies reported that females are facing more mental health issues ${ }^{[2,3]}$. Studies done in India also found that the mental health of women is affected more as com-

*Corresponding Author:

Vanshika Beri,

Amity Institute of Psychology and Allied Sciences, Amity University Campus, Noida, Uttar Pradesh, India;

Email: berivanshika@gmail.com 
pared to men ${ }^{[8,9]}$. Some studies have tried to explain why women are more affected. A study by Beri explained that the period of lockdown has increased the work load on women, especially on employed women. Now they are "working from-for home" that is they are doing their official work and their household work simultaneously which has affected their mental health ${ }^{[10]}$.

The study was done to assess whether depressive tendencies are predicted by coronavirus anxiety. Further, whether gender has any role to play in it or not. The study was done in one part of India (Delhi-NCR), however, the finding will be helpful for various places across the world since all parts of the world are fighting with coronavirus. This study is important because it showed whether people are facing anxiety due to this new phenomenon of coronavirus and whether that in turn is leading to depressive tendency. There are many other challenges like fight for living, efforts for improving financial conditions, occupational workload and so on that the emerging and young adults are facing. Now in addition to those challenges, the imposition of lockdown and a total change in the way of living has further added to their problem, which is leading to deterioration in their mental wellbeing. People who have not been diagnosed with any physical or psychological problems were taken, therefore, depressive tendencies among people who were earlier fine, indicate a gradual decline in health. The study also contributed to the literature of clinical psychology and advancements in the literature of coronavirus.

H1: There would be a significant prediction of depressive tendencies by coronavirus anxiety.

$\mathrm{H} 2$ : There would be significant interaction between gender and coronavirus anxiety on depressive tendencies.

\section{Method}

\subsection{Population}

Simple random sampling method was employed to reach the participants. A total of two-hundred ten participants took part in the study out of which two-hundred four met the inclusion criteria and were therefore included in the study. The demographic details of the participants are given in Table 1.

Table 1. Demographic Details of the Participants

\begin{tabular}{ccc}
\hline & $\mathbf{N}(\mathbf{n}=\mathbf{2 0 4})$ & $\mathbf{\%}$ \\
\hline Gender & & \\
Females & 103 & 50.5 \\
Males & 101 & 49.5 \\
Age & & \\
$20-25$ & 73 & 35.8 \\
$26-30$ & 83 & 40.7 \\
$31-35$ & 48 & 23.5 \\
\hline
\end{tabular}

\subsection{Instruments}

\section{Coronavirus Anxiety Scale.}

The scale is the first published scale validated on large population by Lee ${ }^{[11]}$. It is used to assess COVID-19 related dysfunctional anxiety. The scale consists of five items which are simply added to give a total score. A score of nine and above indicates dysfunctional anxiety. The scale is highly reliable with Cronbach alpha of 0.93 and is highly correlated with other similar scales ${ }^{[1]}$. For the study, english version of the scale was used.

\section{Patient Health Questionnaire-9}

The Patient Health Questionnaire-9 (PHQ-9) is a 9 item self-report questionnaire which is used to assess depressive symptoms ${ }^{[12]}$. The items are simply added to obtain a total score. A low score does not indicate depressive tendency whereas a high score signifies presence of depressive tendencies. The internal consistency of the questionnaire is 0.83 and the correlation between PHQ9 and other two similar scales was $0.63^{[13]}$. For the study, English version of the scale was used.

\section{Design and Procedure}

A google form was formulated using two questionnaires, which were circulated to people over LinkedIn through a simple random sampling method. Participants who met the inclusion criteria (in Table 2) were included in the study. Any past difficulty might contribute to the anxiety or depressive tendency therefore people who were not diagnosed with any physical or psychological disturbances were taken into consideration. The data of the included responses were analyzed using linear regression and two-way ANOVA in SPSS (20).

Table 2. Inclusion and Exclusion Criteria

\begin{tabular}{ccc}
\hline & Inclusion Criteria & Exclusion Criteria \\
\hline 1 & 20- 35 years-old & 19 and below; 36 and above. \\
2 & Residing in Delhi-NCR & Outside Delhi-NCR \\
3 & $\begin{array}{c}\text { People who were not diag- } \\
\text { nosed with any physical or } \\
\text { psychological disturbances }\end{array}$ & $\begin{array}{c}\text { People who were diagnosed with } \\
\text { any physical or psychological } \\
\text { disturbances }\end{array}$ \\
\hline
\end{tabular}

\section{Results}

A simple linear regression was calculated to predict depressive tendencies based on coronavirus anxiety, $\mathrm{b}=.899$, $\mathrm{t}(202)=6.57, p=.000$. A significant regression equation was found $(\mathrm{F}(1,202)=854.60, p=0.00)$ with an $\mathrm{R}^{2}=$ .809. The output is given in Figure 1 . 


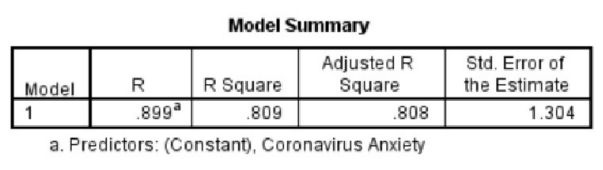

\begin{tabular}{|c|c|c|c|c|c|c|}
\hline \multicolumn{7}{|c|}{ ANOVA ${ }^{a}$} \\
\hline Model & & $\begin{array}{l}\text { Sum of } \\
\text { Squares }\end{array}$ & df & Mean Square & $\mathrm{F}$ & Sig. \\
\hline \multirow[t]{3}{*}{1} & Regression & 1452.877 & 1 & 1452.877 & 854.604 & $.000^{b}$ \\
\hline & Residual & 343.412 & 202 & 1.700 & & \\
\hline & Total & 1796.289 & 203 & & & \\
\hline
\end{tabular}

a. Dependent Variable: Depressive Tendencies

b. Predictors: (Constant), Coronavirus anxiety

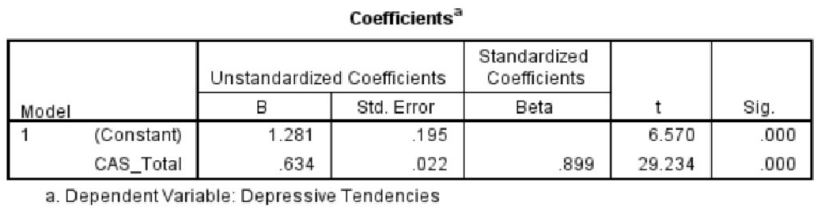

Figure 1. Coronavirus anxiety and depressive tendency: linear regression

Further, two-way ANOVA was used to analyze interaction between gender and coronavirus anxiety on depressive tendencies. The results in table 3 indicate that there is an insignificant difference how males and females are facing depressive tendencies. Finally, there is insignificant interaction between coronavirus anxiety and gender on depressive tendencies.

Table 3. F value for interaction between gender and coronavirus anxiety on depressive tendencies.

\begin{tabular}{cccc}
\hline & df & F & Sig \\
\hline Coronavirus anxiety & 13 & 81.23 & $.000^{* *}$ \\
Gender & 1 & .544 & .462 \\
Coronavirus Anxiety*Gender & 10 & .916 & .520 \\
Error & 179 & & \\
\hline
\end{tabular}

Note: DV- Depressive Tendencies; **- $\mathrm{p}<0.001$

\section{Discussion}

The chemical enemy, naming coronavirus has impacted life of each and every individual in different ways. Many researchers explored these different ways in which people got affected by this virus. The current research specifically focused on impact of coronavirus on mental health of people residing in Delhi-NCR. The analysis of the first hypothesis revealed that there is a strong relation between coronavirus anxiety and depressive tendencies and that the coronavirus anxiety is a predictor of depressive tendency. It means that people who are facing anxiety related to coronavirus are also likely to face depressive tendencies. The findings are consistent with the studies that were done in the past in which people faced anxiety and depression ${ }^{[4,5,6]}$ along with sleep disturbance, adjustment problems, and high perceived stress ${ }^{[2]}$.

Many studies have found that people with chronic diseases are more likely to face anxiety ${ }^{[14,15]}$. However, the present study revealed that anxiety is becoming common among people who were not earlier diagnosed with any physical or psychological disturbance, which is further leading to depressive tendencies. There could be various reasons of why both the variables are so strongly related. For example, there are so many restrictions that are being placed on people in terms of their movement, their hobbies, food items and so on because of which people might feel sadness, unhappiness, heavy heart or bad temper. This might be the reason why coronavirus related anxiety is so strongly related to depressive tendencies.

Further the study revealed that there is an insignificant difference in the level of depressive tendencies faced by males and females. This means that both males and females are experiencing depressive tendencies with the same intensity. Further there is insignificant interaction between gender and coronavirus anxiety on depression tendencies. This means that irrespective of gender, who so ever is facing anxiety related to coronavirus is likely to face depressive tendency. These findings contradict researches done in the past. Most of the research found that females are more likely to face mental health issues as compared to males ${ }^{[8,9,2,3]}$; especially depression ${ }^{[14,16]}$. As per my knowledge, there was no study reporting that both males and females are facing depression and anxiety with the same intensity. Everyone is going through the same problem of sitting inside their homes, fear of going outside and so on. There is a change in the living style of everyone, be it a male or a female. No one can go out or enjoy doing whatever one might be doing earlier. Since everyone is going through more or less the same situation, therefore, they might be facing the same issues and problems. It is difficult for everyone to adjust with the changes that we all are going through.

\section{Implications, Limitations and Future Sug- gestions}

This paper highlights that the coronavirus related anxiety is leading to depression in both males and females. The emerging and young adults who participated in the study were the one's who did not have any physical or psychological problem but are now facing depressive tendency because of coronavirus related anxiety. This shows how the current scenario is impacting our young gener- 
ation. It is important to spread awareness regarding how our mental health is getting affected due to this situation.

There are a few limitations of this paper. Firstly, the paper did not take into consideration factors like marital status, economic condition and so on. Future researchers can include these variables.

\section{Conclusions}

The current study was done to see the impact of coronavirus related anxiety on depressive tendencies. The findings indicate that the coronavirus anxiety is strongly related to depressive tendencies and that the coronavirus anxiety is a predictor of depressive tendency. However, two-way ANOVA indicated that there is an insignificant difference as to how males and females face depressive tendencies. Finally, there is insignificant interaction between gender and coronavirus anxiety on depressive tendencies.

\section{Acknowledgement}

I would like to thank all the participants who gave their time to this research.

\section{Funding}

None

\section{Declaration of Interest}

Declaration of Interest: None

\section{References}

[1] Ducharme, J. (March, 11, 2020). World health organization declares COVID-19 a 'pandemic'. Here's what that means. Retrieved from: The WHO Just Declared Coronavirus COVID-19 a Pandemic| Time.

[2] Rossi, R., Socci, V., Talevi, D., Mensi, S., Niolu, C., Pacitti, F., ... \& Di Lorenzo, G. (2020). COVID-19 pandemic and lockdown measures impact on mental health among the general population in Italy. Frontiers in psychiatry, 11, 790. https://doi.org/10.3389/ fpsyt.2020.00790.

[3] Gualano, M. R., Lo Moro, G., Voglino, G., Bert, F., \& Siliquini, R. (2020). Effects of Covid-19 lockdown on mental health and sleep disturbances in Italy. International journal of environmental research and public health, 17(13), 4779. https://doi. org/10.3390/ijerph17134779.

[4] Pieh, C., Budimir, S., \& Probst, T. (2020). The effect of age, gender, income, work, and physical activity on mental health during coronavirus dis- ease (COVID-19) lockdown in Austria. Journal of psychosomatic research, 136, 110186. https://doi. org/10.1016/j.jpsychores.2020.110186.

[5] Wang, C., Pan, R., Wan, X., Tan, Y., Xu, L., McIntyre, R.S., Choo, F.N., Tran, B., Ho, R., Sharma, V.K., \& Ho, C. (2020b). A longitudinal study on the mental health of general population during the COVID-19 epidemic in China. Brain, Behavior, and Immunity, 87, 40-48. https:// doi.org/10.1016/ j.bbi.2020.04.028.

[6] Torales, J., O'Higgins, M., Castaldelli-Maia, J. M., \& Ventriglio, A. (2020). The outbreak of COVID-19 coronavirus and its impact on global mental health. International Journal of Social Psychiatry, 0020764020915212. https://doi. org/10.1177/0020764020915212.

[7] Sathyamurthi, K., Anjali, U.S., Kumar, A. P., Babu, A., Silpa, C.B., Hemalatha, P. \& Krishna, J. (2020). Mental Health Status of Indian population during Covid19 outbreak. International research journal of education and technology, 1(2), 52-63.

[8] Raju J, Asirvatham R. \& Madani A.H. (2021). Impact of lockdown during covid-19 pandemic on psychological wellbeing among healthy working adults. Black Sea Journal of Public and Social Science, 4(1), 34-41.

[9] Sharma, N., \& Vaish, H. (2020). Impact of COVID-19 on mental health and physical load on women professionals: an online cross-sectional survey. Health care for women international, 1-18. https://doi.org/10.1080/07399332.2020.1825441.

[10] Beri, V (2021). Impact of COVID-19 on mental health of employed women residing in Delhi-NCR, India: Mediating role of working from-for home. Health care for women international, https://doi.org /10.1080/07399332.2021.1882463.

[11] Lee, S.A. (2020) Coronavirus Anxiety Scale: A brief mental health screener for COVID-19 related anxiety. Death Studies, 44(7), 393-401. DOI: $10.1080 / 07481187.2020 .1748481$

[12] Kroenke, K., Spitzer, R.L. \& Williams, J.B.W. (2001). The PHQ-9: validity of a brief depression severity measure. Journal of General Internal Medicine, 16(9), 606-613. http://dx.xoi.org/10.1046/ j.1525-1497.2001.016009606.x.

[13] Chagas M.H., Tumas V., Rodrigues G.R., Machado-de-Sousa J.P., Filho A.S., Hallak J.E. \& Crippa J.A. (2013). Validation and internal consistency of patient health questionnaire-9 for major depression in parkinson's disease. Age Ageing, 42(5), 645-9. DOI: 10.1093/ageing/aft065.

[14] Mazza, C., Ricci, E., Biondi, S., Colasanti, M., 
Ferracuti, S., Napoli, C., Roma, P. (2020). A nationwide survey of psychological distress among Italian people during the COVID19 pandemic: immediate psychological responses and associated factors. International Journal of Environmental Research and Public Health, 17(9), 3165. https://doi.org/10.3390/ ijerph17093165.

[15] Özdin, S. \& Özdin, S. B. (2020). Levels and predictors of anxiety, depression and health anxiety during COVID-19 pandemic in Turkish society: The importance of gender. International Journal of Social Psychiatry, 66(5) 504-511. 10.1177/0020764020927051.

[16] Lei, L., Huang, X., Zhang, S., Yang, J., Yang, L., $\mathrm{Xu}, \mathrm{M}$. (2020). Comparison of prevalence and associated factors of anxiety and depression among people affected by versus people unaffected by quarantine during the covid-19 epidemic in southwestern China. Medical Science Monitor, 26, e924609. https://doi.org/10.12659/MSM.924609. 